\title{
Canal transportation and centering ability of curved root canals prepared using rotary and reciprocating systems
}

\author{
Marlos Barbosa-Ribeiro ${ }^{1}$, Silvio José Albergaria², Maria de Fátima Gesteira Malvar², \\ lêda Margarida Crusoé-Rebello², Brenda Paula Figueiredo de Almeida Gomes ${ }^{1}$, Fabíola Bastos de Carvalho
}

${ }^{1}$ Universidade Estadual de Campinas - UNICAMP, Piracicaba Dental School, Department of Restorative Dentistry, Area of Endodontics, Piracicaba, SP, Brazil ${ }^{2}$ Universidade Federal da Bahia - UFBA, Dental School, Department of Dental Clinic, Area of Endodontics, Salvador, BA, Brazil

Received for publication: August 12, 2015 Accepted: September 23, 2015

Correspondence to: Marlos Barbosa-Ribeiro Faculdade de Odontologia de Piracicaba UNICAMP, Área de Endodontia Avenida Limeira, 901

13414-903 - Piracicaba, São Paulo, Brasil Phone: +55 192106 5215. Fax: +55 1921060144

E-mail: ribeiro.marlos@yahoo.com.br

\begin{abstract}
Aim: To evaluate canal transportation and centering ability of Protaper and WaveOne systems in curved root canals by cone-beam computed tomography. Methods: Twenty human molars were randomly divided into two groups according to the system used: Group GP (ProTaper Universal $^{\circledR}$ ) and group GW (WaveOne ${ }^{\mathrm{TM}}$ ). CT scans were performed before and after the chemo-mechanical preparation on three points: $2 \mathrm{~mm}, 3 \mathrm{~mm}$ and $4 \mathrm{~mm}$ from the tooth apex. The cuttings in dentin were measured and results were statistically analyzed. Results: In GP, there was higher percentage in transport at $2 \mathrm{~mm}$ and $4 \mathrm{~mm}$ toward the mesial wall of the tooth root compared to $\mathrm{GW}(\mathrm{p}<0.05)$. There was no difference between the systems regarding their centering ability. Conclusions: None of the systems was able to touch all the dentin walls and stay centered during the chemical-mechanical preparation.
\end{abstract}

Keywords: root canal preparation; endodontics; cone-beam computed tomography.

\section{Introduction}

Development of nickel-titanium (NiTi) rotary instruments provided easier and faster root canal instrumentation ${ }^{1-8}$. Many systems have different designs in their structure to minimize procedural errors and achieve a predictable canal preparation. Wherefore, it is important to evaluate the mechanical action of these files in order to improve and optimize the endodontic instrumentation ${ }^{5,7-12}$.

The ProTaper ${ }^{\circledR}$ rotary system has variable taper and some rigidity due to the considerable amount of metal in its structure. These factors may limit its use in curved and flattened root canals, since the instrument is subject to lock in the cervical third and does not touch properly all dentinal walls ${ }^{13}$. The WaveOne ${ }^{\mathrm{TM}}$ reciprocating system consists of biomechanical preparation with a single file that presents greater flexibility and resistance to cyclic fatigue compared with the conventional NiTi alloy, due to treatment of the M-Wire alloy. In addition, their active part have less variation in taper, which could provide greater control of the instrument by the clinician ${ }^{2,4,9,11,14-19}$.

Cone-beam computed tomography $(\mathrm{CBCT})$ is a modern and noninvasive diagnostic feature with compact equipment, low dose radiation and allows evaluation of detailed images using different settings. It is useful in comparing anatomical structure of the root canal before and after biomechanical preparation, allowing to detect deviations and transportation ${ }^{3,20-23}$. It may also allow assessment 
of centering ability of endodontic instruments that indicate the ability of the instrument to remain centered in the root canal $^{17,24}$.

Continuous evaluation of the mechanical behavior of endodontic files is important to understand their effect on the chemo-mechanical preparation. Thus, the aim of this study was to evaluate canal transportation and centering ability of Protaper and WaveOne systems in curved mandibular molar mesial canals by CBCT.

\section{Material and methods}

After approval by the Ethics Research Committee of the School of Dentistry of Piracicaba, University of Campinas (Protocol number 094/2013), 20 human mandibular molars from the toth bank of the Institute of Health Sciences, Federal University of Bahia were selected. The method described by Estrela et al. ${ }^{22}$ was used to determine the degree of root curvature. Only teeth with apical curvature between $20^{\circ}$ and $40^{\circ}$ in the mesial-distal direction were selected.

The tooth crowns were cross-sectioned with a diamond disc (Buehler, Lake Buff, IL, USA) mounted in a metallographic cutter (ISOMET 1000, Buehler) in low rotation $(300 \mathrm{rpm})$ and under constant water irrigation to standardize the root length at $16 \mathrm{~mm}$. Pulp tissue removal from pulp chamber was performed with Endo-Z bur (DentsplyMaillefer, Ballaigues, Switzerland).

\section{Preparation of the specimens}

The teeth were randomly divided into 2 groups, $n=10$ per group (GP and GW) (Table 1), identified and mounted in a jaw and attached with silicone impression material. These procedures allowed positioning for tomographic scanning and for standardizing the test for scans before and after root canal procedures. The mesial-buccal roots were marked in all their extension with a gutta-percha point in order to serve as a reference for the measurement on the images (Figure 1).

\section{Chemo-mechanical preparation (CMP) of root canals}

The working length (WL) was established at $15.0 \mathrm{~mm}$. The CMP was performed according to the manufacturer's recommendations (Table 1). In GW were first used \#013 and \#016 PathFiles (Dentsply-Maillefer) to obtain the glide path of the root canal; in GP the glide path was obtained with $\# 10$ and \#15 hand files. In both groups, irrigation/aspiration at each file exchange was performed with $5.0 \mathrm{~mL}$ of $1 \%$ $\mathrm{NaOCl}$ using a disposable syringe and needle. After completing CMP, a final flush was done with $3.0 \mathrm{~mL}$ of

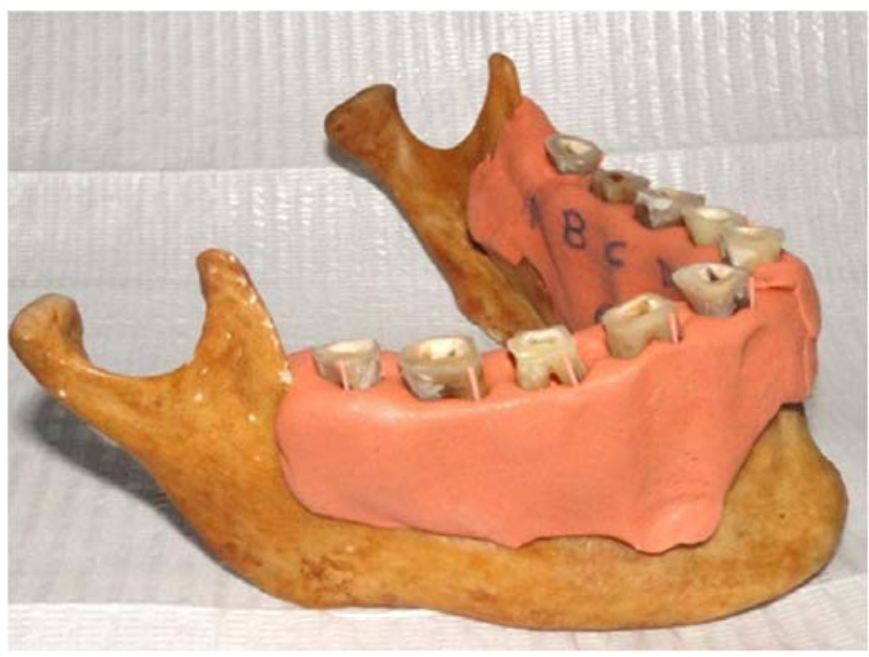

Fig. 1. Specimens mounted in a jaw and attached with silicone impression material for positioning the scanner.

$17 \%$ EDTA for 3 min followed by $3 \mathrm{~mL}$ of $1 \% \mathrm{NaOCl}$. Finally, root canals were dried with absorbent paper points.

The diameter D0 of the final file was standardized at $0.25 \mathrm{~mm}$ for both groups, whereas the time spent by each instrument in GP and the progressive insertion of the file in GW was 30 s. In GP the "shaping files" were introduced with brush movements on all root canal walls. The "finishing files" in GP and the "primary file" of GW were introduced with slight apical pressure in pecking motion up to the WL. The electric engine used for instrumentation in both groups was X-Smart Plus (Dentsply-Maillefer) with speed and torque pre-established by the handset. All groups were prepared by a single experienced clinician.

\section{Analysis of images}

Teeth were scanned before and after CMP perpendicular to the beam of the Kodak 9000 3D unit (Trophy, France) CBCT device with the following settings: $72 \mathrm{kV}, 12 \mathrm{~mA}$ and $0.1 \mathrm{~mm}$ voxel size. The specimen was allocated in a styrofoam box with water to attenuate the radiation beams and simulate the clinical conditions of the soft tissue. Calculation and comparison of all scans were made by the CS 3D imaging software at $2 \mathrm{~mm}$, $3 \mathrm{~mm}$ and $4 \mathrm{~mm}$ from the apex (Figure 2). References were taken in axial, parasagittal and paracoronal dimensions and the distances mesial-canal, canal diameter, distal-canal and mesialdistal, as well as buccal-canal, canal diameter, lingual-canal and buccal-lingual were measured (Figure 3).

The parameters used to evaluate the centering ability followed the proportionality method proposed by Gambill et al. ${ }^{17}$, using the following formula: $\mathrm{D} 1=\left(\mathrm{x}-\mathrm{x}^{\prime}\right) /\left(\mathrm{x}_{1}-\mathrm{x}_{1}{ }^{\prime}\right)$ in the buccal-lingual direction and $\mathrm{D} 2=\left(\mathrm{z}-\mathrm{z}^{\prime}\right) /\left(\mathrm{z}_{1}-\mathrm{z}_{1}{ }^{\prime}\right)$, mesial-

Table 1. Kinematics description and the files used in this study. (Manufacturer: DentsplyMaillefer, Ballaigues, Switzerland)

\begin{tabular}{lcccc}
\hline System & Motion & Cutting & File & Tip \\
angle & Slightly positive & SX, S1, S2, F1, F2 & No cutting \\
${\text { ProTaper Universal }{ }^{2}}_{\text {WaveOne }^{\mathrm{TM}}}$ & $\begin{array}{c}\text { Continuous rotation } \\
\text { Reciprocation }\end{array}$ & Reverse & Primary & No cutting \\
\hline
\end{tabular}



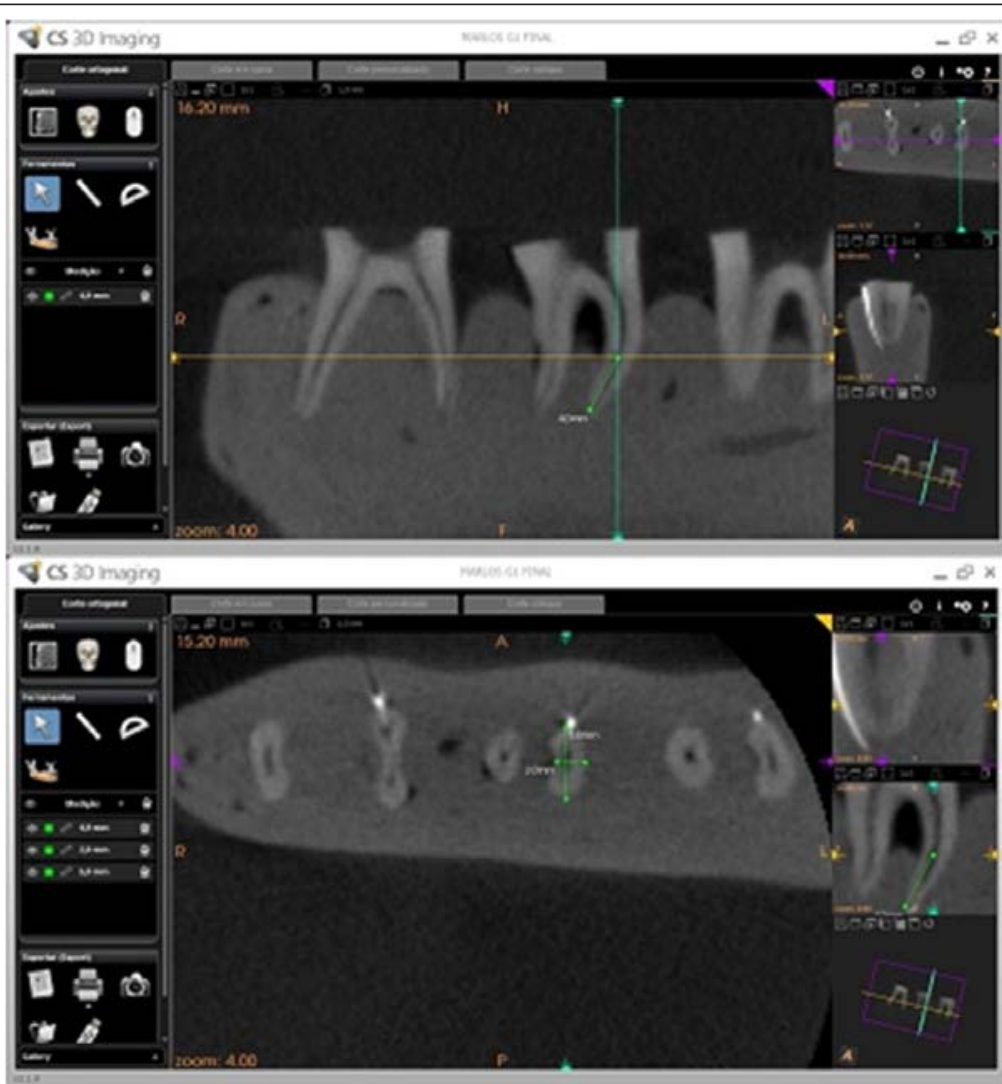

Fig. 2. Computer screen displaying the multidimensional window of software CS 3D Imaging recording the images according to the selected cuts.
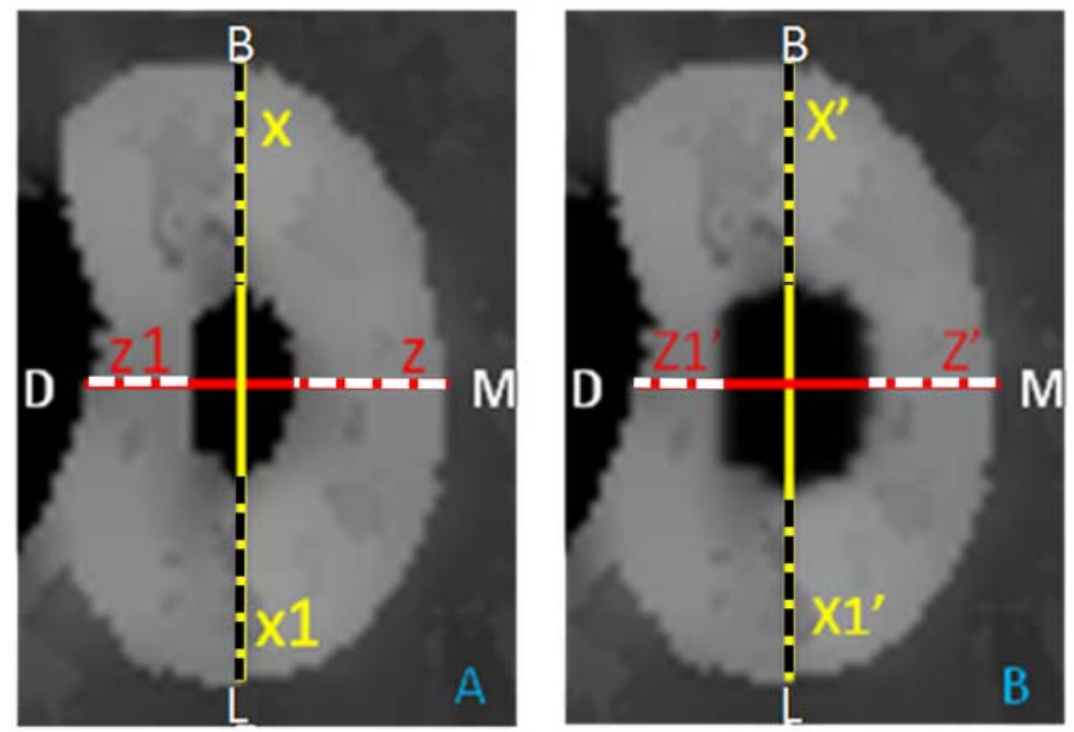

Fig. 3. Representative image of a CBCT scan before (A) and after CMP (B).

distal direction. If these numbers are not equal, the lower figure is considered as numerator of the ratio. Result 1 indicates perfect centering. The direction of the canal transportation was observed using the same method by the following formula: $\mathrm{T} 1=\left(\mathrm{x}-\mathrm{x}^{\prime}\right)-\left(\mathrm{x}_{1}-\mathrm{x}_{1}{ }^{\prime}\right)$ and $\mathrm{T} 2=\left(\mathrm{z}-\mathrm{z}^{\prime}\right)-$ $\left(z_{1}, z_{1}{ }^{\prime}\right)^{4}$. Result 0 (zero) means that there was no canal transport, positive (buccal/distal transportation), negative (lingual/mesial transportation).

For paired samples was used repeated-measures ANOVA and Tukey's multiple-comparison test or the Friedman test for nonparametric data. The significance level was set at $5 \%$. Each tooth was evaluated at points 2, 3 and $4 \mathrm{~mm}$ in the buccal-lingual and mesial-distal direction. 


\section{Results}

The results showed a high rate of transportation at 2 $\mathrm{mm}$ level $(\mathrm{p}<0.05)$ for the mesial wall of the root canal in GP (Table 2). Comparing the groups, both presented a high rate of mesial transportation at the $4 \mathrm{~mm}$ level $(\mathrm{p}<0.05)$.

In relation to the centering ability, both tested systems left untouched dentine areas (Table 3) and created transport the root canal towards buccal and/or mesial directions.

\section{Discussion}

The CBCT is an effective tool for comparisons between mechanical performances of endodontic instruments and has been widely used to evaluate area, volume, centering ability of instruments and transportation of the root canal ${ }^{4-5,7}$. In this study we used the CS 3D imaging software (Kodak Dental Systems), which allows performing measurements in detail and the analysis of the same point on different dimensions at the multidimensional reconstructions. The fidelity of this examination is the standard for this kind of assessment.

During the CMP of curved root canals, files tend to be linear over the entire canal and have more wear of inner wall of curvature in the coronal third and toward the outer edge of the root ${ }^{20,23}$. Several studies have shown little decentralization and transportation of root canal during cleaning and shaping due to the flexibility of NiTi automated instruments s, $^{3,9-10,14,19,24-26}$. The degree of curvature of the root canal, file taper and the canal flattening might influence negatively the $\mathrm{CMP}^{13}$. It could be the reasons why in both groups there was a higher rate of mesial transportation. In GP, there was a higher rate of transportation in the mesial canal wall, which reinforces the above-mentioned idea.

The cross section and the surface treatment of the WaveOne system increase their mechanical efficiency and contribute to a balanced action in CMP. However, the time required for instrumentation seems to influence directly the appropriate modeling of the root canal system. This may have been the reason why WaveOne did not produce significant results in this study, corroborating with the results of Kim et al. ${ }^{6}$ (2012). This indicates that the WaveOne singlefile system does not create excessive transportation compared with ProTaper, allowing inferring that the reciprocating systems are an effective alternative and tend to be routinely used in endodontic treatment, being a safe technique.

According to Berutti et al. ${ }^{2}$ (2012), the reciprocating movement allows a more centralized CMP compared to continuous rotary motion, especially in the apical third. The authors report that quality in debris removal is similar to the sequence of ProTaper instruments up to F2 file. In this study, despite of WaveOne having touched less mesial and lingual walls of the root canal than ProTaper, it remained more centered in the root canal, in the mesial-distal direction as well as in the buccal-lingual one. However, the fact that the instrument remained centered does not necessarily imply that a balanced motion and who managed to touch properly on the canal walls, possibly due to a clamping of the file in the coronal third.

Versiani et al. ${ }^{18}$ (2013), assessed by micro-computed tomography the instrumentation of oval canals by WaveOne, Reciproc, Self-ajusting (SAF) and ProTaper systems. The authors observed areas with untouched dentin. ProTaper and WaveOne systems obtained similar results and the lowest untouched areas compared to SAF. Thus, it is possible to admit that frequently the number of untouched areas by the files is due either to a deficiency of the technique, but also to anatomical irregularities. This study corroborated this idea, since in both groups it was observed in certain points that the instrument was not able to touch the dentinal walls. This fact may result in clinical implications where portions of the root canal could remain contaminated, especially in the apical third, and this can maintain the infection.

A differential of this study is the fact that it considered the centering ability and canal transportation in both root directions (buccal-lingual and mesial-distal) and not only in one direction (usually the mesial-distal) as most studies $\mathrm{do}^{4,17,24}$, allowing a wide approach to the mechanical action of the tested files.

Considering the methodological limitations of this

Table 2. Mean and standard deviation of transportation of root canal.

\begin{tabular}{llllll}
\hline Direction & Group & $\mathbf{2 m m}$ & $\mathbf{3 m ~}$ & $\mathbf{4 m ~}$ & $\mathrm{p}$ value \\
Buccal-lingual & GP & $0 \pm 0.1$ & $0 \pm 0.3$ & $0.1 \pm 0.3$ & 0.875 \\
& GW & $-0.2 \pm 0.3$ & $-0.1 \pm 0.3$ & $0 \pm 0.4$ & 0.521 \\
Mesial-distal & GP & $-0.04 \pm 012^{\star *}$ & $0.13 \pm 0.2$ & $-0.1 \pm 0.2$ & $0.039^{*}$ \\
& GW & $0.06 \pm 0.2$ & $0.05 \pm 0.3$ & $0.07 \pm 0.2$ & 0.986 \\
\hline
\end{tabular}

* ANOVA with repeated measures, ${ }^{* *}$ Tukey's test $(p<0.05)$.

Table 3. Mean and Standard Deviation of centering ability.

\begin{tabular}{llllll}
\hline Group & Distance & \multicolumn{3}{c}{ Point } & p-value \\
\cline { 3 - 5 } & & $2 \mathrm{~mm}$ & $3 \mathrm{~mm}$ & $4 \mathrm{~mm}$ & \\
GP & Buccal-distal & $-0.22 \pm 0.2$ & $-0.22 \pm 0.2$ & $-0.16 \pm 0.1$ & \\
& Mesial-lingual & $-0.09 \pm 0.1$ & $-0.07 \pm 0$ & $-0.09 \pm 0.1$ & $\mathrm{p}>0.05$ \\
\multirow{2}{*}{ GW } & Buccal-distal & $-0.15 \pm 0.1$ & $-0.21 \pm 0.1$ & $-0.14 \pm 0.1$ & \\
& Mesial-lingual & $-0.16 \pm 0.1$ & $-0.14 \pm 0.1$ & $-0.13 \pm 0.1$ & \\
\hline
\end{tabular}

Friedman test $(p<0.05)$. 
study, particularly the use of CBCT instead of microcomputed tomography that has more accuracy, we conclude that there was a low percentage in the centering ability of the tested instruments with a considerable index of partially or completely untouched dentinal walls during CMP. The degree of transportation does not seem to compromise the preparation of root canals since both automated systems proved being able of providing good shaping.

\section{References}

1. Arias A, Perez-Higueras JJ, Macorra JC. Differences in cyclic fatigue resistance at apical and coronal levels of reciproc and waveone new files. J Endod. 2012; 38: 1244-8.

2. Berutti E, Paolino DS, Chiandussi G, Alovisi M, Cantatore G, Castellucci $A$, et al. Root canal anatomy preservation of WaveOne reciprocating files with or without glide path. J Endod. 2012; 38: 101-4.

3. Gao Y, Cheung GS, Shen Y, Zhou X. Mechanical behavior of ProTaper universal F2 finishing file under various curvature conditions: a finite element analysis study. J Endod. 2011; 37: 1446-50.

4. Gergi R, Rjeily JA, Saber J, Naaman A. Comparison of canal transportation and centering ability of twisted files, Pathfile-ProTaper system, and stainless steel hand K-Files by using computed tomography. J Endod. 2010; 36: 904-7.

5. Hartmann MSM, Barletta FB, Fontanella VRC, Vanni JR. Canal transportation after root canal instrumentation: a comparative study with computed tomography. J Endod. 2007; 33: 962-5.

6. Kim HC, Kwak SW, Cheung GS, Ko DH, Chung SM, Lee W. Cyclic fatigue and torsional resistance of two new nickel-titanium instruments used in reciprocation motion: Reciproc versus WaveOne. J Endod. 2012; 38: $541-4$

7. Moraes SH, Gonçalves M, Tanomaru Filho M, Bonetti Filho I. Cutting ability of nickel-titanium rotary systems ProTaper, Mtwo and K3. RSBO: Rev Sul-Bras Odontol. 2012; 9: 177-82.

8. Ozer SY. Comparison of root canal transportation induced by three rotary systems with noncutting tips using computed tomography. Oral Surg Oral Med Oral Pathol Oral Radiol Endod. 2011; 111: 244-50.

9. Basmaci F, Oztan MD, Kiyan M. Ex vivo evaluation of various instrumentation techniques and irrigants in reducing $\mathrm{E}$. faecalis within root canals. Int Endod J. 2013; 46: 823-30.

10. Elsherief SM, Zayet MK, Hamouda IM. Cone-beam computed tomography analysis of curved root canals after mechanical preparation with three nickel-titanium rotary instruments. J Biomed Res. 2013; 27: 326-35.

11. Castelló-Escrivá R, Alegre-Domingo T, Faus-Matoses V, Román-Richon S, Faus-Llácer VJ. In Vitro Comparison of Cyclic Fatigue Resistance of ProTaper, WaveOne, and Twisted Files. J Endod. 2012; 38: 1521-4.

12. Kim HC, Kwak SW, Cheung GS, Ko DH, Chung SM, Lee W. Cyclic fatigue and torsional resistance of two new nickel-titanium instruments used in reciprocation motion: Reciproc versus Waveone. JEndod. 2012; 38: 541-4.

13. Park SK, Kim YJ, Shon WJ, You SY, Moon YM, Kim HC, et al. Clinical efficiency and reusability of the reciprocating nickel-titanium instruments according to the root canal anatomy. Scanning. 2013; 36: 246-51.

14. Aguiar CM, Mendes DA, Câmara AC, Figueiredo JÁ. Evaluation of the centering ability of the ProTaper Universal rotary system in curved roots in comparison to Nitiflex files. Aust Endod J. 2009; 35: 174-9.

15. Berutti E, Paolino DS, Chiandussi G, Alovisi M, Cantatore G, Castellucci $A$, et al. Effect of canal length and curvature on working length alteration with WaveOne reciprocating files. J Endod. 2011; 37: 1687-90.

16. Burklein S, Hinschitza K, Dammaschke T, Schafer E. Shaping ability and cleaning effectiveness of two single-file systems in severely curved root canals of extracted teeth: Reciproc and WaveOne versus Mtwo and ProTaper. Int Endod J. 2012; 45: 449-61.
17. Gambill JM, Alder M, Del Rio CE. Comparison of nickel-titanium and stainless steel hand-file instrumentation using computed tomography. J Endod. 1996; 22: 369-75.

18. Versiani MA, Leoni GB, Steier L, De-Deus G, Tassani S, Pécora JD, et al. Micro-computed tomography study of oval-shaped canals prepared with the self-adjusting file, Reciproc, WaveOne, and ProTaper universal systems. J Endod. 2013; 39: 1060-6.

19. Webber J, Machtou P, Pertot W, Kuttler S, Ruddle C, West J. The WaveOne single-file reciprocating system. Clin Tech. 2011; 1: 28-33.

20. Tepel J, Schäfer E, Hoppe W. Properties of endodontic hand instruments used in rotary motion. Part I. Cutting efficiency. J Endod. 1995; 21: 118-21.

21. Torres MGG, Campos PSF, Segundo NPN, Ribeiro R, Navarro M, Crusoé-Rebello I. [Evaluation of referential dosages obtained by ConeBeam Computed Tomography examinations acquired with different voxel sizes]. Dent Press J Orthod. 2010; 15: 42-3. Portuguese.

22. Estrela C, Bueno MR, Sousa-Neto MD, Pécora JD. Method for determination of root curvature radius using cone-beam computed tomography images. Braz Dent J. 2008; 2: 114-8.

23. Rödig T, Hülsmann M, Kahlmeieir C. Comparison of roof canal preparation with two rotary NiTi instruments: ProFile .04 and GT rotary. Int Endod J. 2007; 40: 553-62.

24. Gergi R, Arbab-Chirani R, Osta N, Naaman A; Micro-computed tomographic evaluation of canal transportation instrumented by different kinematics rotary nickel-titanium instruments. J Endod. 2014; 40: 1223-7.

25. Junaid A, Freire LG, da Silveira Bueno CE, Mello I, Cunha RS. Influence of single-file endodontics on apical transportation in curved root canals: an ex vivo micro-computed tomographic study. J Endod. 2014; 40: 717-20.

26. Pasternak-Júnior B, Sousa-Neto MD, Silva RG. Canal transportation and centring ability of RaCe rotary instruments. Int Endod J. 2009; 42: 499506. 